\title{
The association of lipoprotein(a) and intraplaque neovascularization in patients with carotid stenosis: a retrospective study
}

\author{
Shuang Xia ${ }^{2 \dagger}$, Weida Qiu ${ }^{1 \dagger}$, Anping Cai ${ }^{2}$, Bo Kong ${ }^{2}$, Lan Xu ${ }^{2}$, Zejia Wu² and Liwen Li ${ }^{2 *}$
}

\begin{abstract}
Background: Lipoprotein(a) is genetically determined and increasingly recognized as a major risk factor for arteriosclerotic cardiovascular disease. We examined whether plasma lipoprotein(a) concentrations were associated with intraplaque neovascularization (IPN) grade in patients with carotid stenosis and in terms of increasing plaque susceptibility to haemorrhage and rupture.

Methods: We included 85 patients diagnosed with carotid stenosis as confirmed using carotid ultrasound who were treated at Guangdong General Hospital. Baseline data, including demographics, comorbid conditions and carotid ultrasonography, were recorded. The IPN grade was determined using contrast-enhanced ultrasound through the movement of the microbubbles. Univariate and multivariate binary logistic regression analyses were used to evaluate the association between lipoprotein(a) and IPN grade, with stepwise adjustment for covariates including age, sex, comorbid conditions and statin therapy (model 1), total cholesterol, triglyceride, low-density lipoprotein cholesterol calculated by Friedwald's formula, high-density lipoprotein cholesterol, apolipoprotein A and apolipoprotein B (model 2), maximum plaque thickness and total carotid maximum plaque thickness, degree of carotid stenosis and internal carotid artery (ICA) occlusion (model 3).

Results: Lipoprotein(a) was a significant predictor of higher IPN grade in binary logistic regression before adjusting for other risk factors (odds ratio [OR] 1.238, 95\% confidence interval [CI] $(1.020,1.503), P=0.031)$. After adjusting for other risk factors, lipoprotein(a) still remained statistically significant in predicting IPN grade in all model. (Model 1: OR 1.333, 95\% Cl 1.074, 1.655, $P=0.009$; Model 2: OR 1.321,95\% Cl 1.059, 1.648, $P=0.014$; Model 3: OR 1.305, 95\% Cl 1.045, $1.628, P=0.019)$. Lp(a) $\geq 300 \mathrm{mg} / \mathrm{L}$ is also significantly related to IPN compare to $<300 \mathrm{mg} / \mathrm{L}(\mathrm{OR} 2.828,95 \% \mathrm{Cl} 1.055$, $7.580, P=0.039$ ) as well as in model 1 , while in model 2 and model 3 there are not significant difference.
\end{abstract}

Conclusions: Plasma lipoprotein(a) concentrations were found to be independently associated with higher IPN grade in patients with carotid stenosis. Lowering plasma lipoprotein(a) levels may result in plaque stabilization by avoiding IPN formation.

Keywords: Contrast-enhanced ultrasound, Lipoprotein(a), Intraplaque neovascularization, Carotid stenosis, Cardiovascular events

*Correspondence: gdghllw@163.com

†Shuang Xia and Weida Qiu contributed equally to the work

2 Department of Cardiology, Guangdong Cardiovascular Institute, Guangdong Provincial People's Hospital, Guangdong Academy

of Medical Sciences, 106 of Zhongshan 2nd Road, Guangzhou 510100,

Guangdong, China

Full list of author information is available at the end of the article

\section{Background}

Due to recent medical developments, many carotid artery wall imaging methods are available to diagnose and assess carotid stenosis, such as ultrasound, computed tomography, magnetic resonance imaging, and 
even catheter-based angiography [1]. However, few methods can detect intraplaque neovascularization (IPN), which increases the susceptibility to haemorrhage and rupture of the plaque [2] that are also expensive and inconvenient to deal with in terms of repeated examinations. Contrast-enhanced ultrasound (CEUS) can reliably detect IPN [3] through identifying the movement of the contrast microbubbles within the plaque [4].

Lipoprotein(a) (Lp(a)), formed from an apolipoprotein (apo) B-100 covalently linked to apo(a), is a low-density lipoprotein (LDL)-like protein which is genetically determined and increasingly recognised as a major risk factor for ASCVD [5]. Previous studies have demonstrated a strong and independent association between $\mathrm{Lp}(\mathrm{a})$ and carotid artery disease [6] and $\mathrm{Lp}(\mathrm{a})$ independently predict carotid atherosclerosis progression [7]. However, for a great degree of homology between apo(a) and plasminogen [8], lots of studies considered the Lp(a) fragments showed an anti-angiogenesis role in vitro $[9,10]$. On the contrast, there are also a great deal of conflicting reports postulated $\mathrm{Lp}(\mathrm{a})$ induced angiogenesis [11] while others demonstrated a neutral effect on angiogenesis [12], engendering considerable controversy. So, whether $\mathrm{Lp}(\mathrm{a})$ is associate with IPN across the plaque, affecting its stability, is worth pondering.

This research aimed to study the association between IPN and plasma Lp(a) concentrations and analyse the role of $\operatorname{Lp}(\mathrm{a})$ in relation to the carotid artery in patients with carotid stenosis using CEUS.

\section{Methods}

\section{Study design and population}

This retrospective study enrolled 85 consecutive patients who were diagnosed with carotid stenosis using carotid artery ultrasonography (US) in Guangdong General Hospital, China, from January 2017 to January 2020. The inclusion criteria were as follows: (1) carotid stenosis confirmed using carotid artery ultrasonography, (2) absence of clinical contraindications for CEUS, and (3) $\geq 18$ years of age. The exclusion criteria were: (1) having undergone previous carotid endarterectomy, (2) no outcome data concerning $\mathrm{Lp}(\mathrm{a})$, and (3) declining to be involved initially or in follow-up. All patients underwent CEUS after being diagnosed with carotid stenosis using carotid artery ultrasonography. Clinical histories, along with demographic and clinical data, were recorded for all patients at admission. All patients provided written informed consent. This retrospective investigation was approved by the local institutional review board as well as performed in accordance with the Declaration of Helsinki.

\section{Laboratory Measurements}

All fasting venous blood samples were collected during hospital admission before undergoing CEUS. Serum Lp(a) levels were measured through a murine monoclonal antibody (E022-1-1, Bioroyee, Beijing, China) involving latex turbidimetric method. Cholesterol (TC), triglyceride (TG), low-density lipoprotein cholesterol (LDL-C), high-density lipoprotein cholesterol (HDL-C), apolipoprotein(apo) A and apo B levels were determined by chemiluminescence method using an auto-analyser. Friedwald's formula (TC -HDL-C$\mathrm{TG} / 2.2)$ was used to calculate LDL- $\mathrm{C}^{(\mathrm{F})}$.

\section{US examinations of the carotid artery}

Carotid US examinations were performed in all participants at screened visit. Focal structures protruding into carotid lumen with a height $>1.5 \mathrm{~mm}$ or $50 \%$ intima-media thickness was defined as atherosclerotic plaques [13]. Maximun vertical distance from the top of plaque to adventitia interface of lumen was measured as maximum internal carotid artery (ICA) plaque thickness. Total maximum plaque thickness was the cumulative total by bilateral maximum ICA plaques thickness. The degree of ICA stenosis was divided into 4 groups: mild, $<50 \%$; moderate, 50-69\%; severe, $70-99 \%$ [14]; and occlusion, without signal of blood flow.

\section{CEUS examinations of the carotid artery}

Carotid CEUS examinations were performed by a researcher who is blinded to the patients' histories and characteristics, using a GE Vivid E95 or Philips IU elite diasonograph contrast model and a high-frequency superficial probe. CEUS was performed with an ultrasound contrast agent, SonoVue. An initial bolus injection of $1.6 \mathrm{~mL}$ of contrast agent was quickly administered into the median cubital vein in $2-3 \mathrm{~s}$, immediately followed by $3 \mathrm{~mL}$ of $0.9 \%$ normal saline solution at the same speed. Ultrasound cine-loops were then recorded over 15-30 s. The images at $3 \mathrm{~s}$ before and 5 min after contrast agent was introduced into the carotid artery lumen were stored for real-time dynamic analysis. IPN grade was determined using CEUS grade as follows: 0 , no visible microbubbles in the plaque; 1 , minimal microbubbles restricted to adventitial side or shoulder of the plaque; or 2, microbubbles spread all over the plaque [15]. We stratified participants into one of two groups based on their CEUS grade, that is, a CEUS grade on both sides that added up to greater than 
or equal to 2 was used to define an IPN group whereas a CEUS grade on both sides that added up to fewer than 2 was used to define a no IPN group.

\section{Statistical analysis}

All descriptive data consistent with normal distribution are expressed as mean value \pm standard deviation, with the rest expressed as median (interquartile range). Discrete data are presented as frequencies and percentages. A Student's t-test was used to evaluate continuous variables showing a normal distribution and a MannWhitney U-test was used to evaluate variables that show a skewed distribution, while categorial variables were performed using Fisher's exact test. Differences in baseline characteristics were examined between IPN group versus No IPN group (Table 1) and $L p(a) \geq 300 \mathrm{mg} / \mathrm{L}$ $\mathrm{vs}<300 \mathrm{mg} / \mathrm{L}$ (Table 2). Spearman's correlation analysis was further performed to analyse the relationship between $\mathrm{Lp}(\mathrm{a})$ and maximum ICA plaque thickness, total ICA maximum plaque thickness, degree of carotid stenosis and ICA occlusion, respectively. Univariate binary logistic regression analyses were used to determine the association between LP(a) and IPN grade (IPN group vs No IPN group). OR and 95\% CI was reported. Multivariate binary logistic regression analyses were then performed to evaluate the association between $\mathrm{Lp}(\mathrm{a})$

Table 1 Baseline characteristics comparisons between IPN group and No IPN group of the 85 participants

\begin{tabular}{|c|c|c|c|c|}
\hline Variables & Overall $(n=85)$ & IPN group $(n=36)$ & No IPN group $(n=49)$ & $P$ value \\
\hline \multicolumn{5}{|l|}{ General conditions and Comorbid conditions } \\
\hline Age (year) & $68.48 \pm 8.78$ & $70.17 \pm 9.06$ & $67.24 \pm 8.45$ & 0.130 \\
\hline Male sex, n (\%) & $63(74.1 \%)$ & $27(75 \%)$ & $36(73.5 \%)$ & 0.874 \\
\hline Hypertension, n (\%) & $60(70.6 \%)$ & $27(75 \%)$ & $33(67.3 \%)$ & 0.444 \\
\hline Diabetes mellitus, n (\%) & $26(30.6 \%)$ & $14(38.9 \%)$ & $12(24.5 \%)$ & 0.155 \\
\hline Cerebral infraction, n (\%) & $21(24.7 \%)$ & $7(19.4 \%)$ & $14(28.6 \%)$ & 0.335 \\
\hline Coronary heart disease, n (\%) & $38(44.7 \%)$ & $17(47.2 \%)$ & $21(42.9 \%)$ & 0.689 \\
\hline Smoking history, n (\%) & $20(23.5 \%)$ & $6(16.7 \%)$ & $14(28.6 \%)$ & 0.201 \\
\hline Statin therapy, n (\%) & 79 (92.9\%) & $33(91.7 \%)$ & $46(93.9 \%)$ & 0.695 \\
\hline \multicolumn{5}{|l|}{ Serum lipid } \\
\hline $\operatorname{Lp}(a)(m g / L) *$ & $184(96.5-370)$ & $260(92-427.75)$ & $173(100-258.5)$ & 0.018 \\
\hline $\mathrm{TC}(\mathrm{mmol} / \mathrm{L})$ & $4.49 \pm 1.21$ & $4.44 \pm 1.10$ & $4.53 \pm 1.29$ & 0.732 \\
\hline $\mathrm{TG}(\mathrm{mmol} / \mathrm{L}) *$ & $1.34(1.04-1.99)$ & $1.44(1.08-2.26)$ & $1.23(0.87-1.66)$ & 0.223 \\
\hline LDL-C (mmol/L) & $2.92 \pm 0.91$ & $2.88 \pm 0.81$ & $2.95 \pm 0.99$ & 0.729 \\
\hline $\mathrm{LDL}-\mathrm{C}^{(\mathrm{F})}(\mathrm{mmol} / \mathrm{L})$ & $2.13 \pm 0.75$ & $2.07 \pm 0.64$ & $2.17 \pm 0.82$ & 0.537 \\
\hline $\mathrm{HDL}-\mathrm{C}(\mathrm{mmol} / \mathrm{L}){ }^{*}$ & $0.99(0.87-1.16)$ & $0.98(0.83-1.16)$ & $1.02(0.88-1.15)$ & 0.778 \\
\hline Apo(a) $(\mathrm{mmol} / \mathrm{L})^{*}$ & $1.16(1.01-1.28)$ & $1.13(1.00-1.25)$ & $1.16(1.02-1.30)$ & 0.593 \\
\hline $\mathrm{Apo}(\mathrm{b})(\mathrm{mmol} / \mathrm{L})^{*}$ & $0.79(0.64-1.01)$ & $0.77(0.63-0.94)$ & $0.80(0.64-1.04)$ & 0.536 \\
\hline \multicolumn{5}{|l|}{ Carotid plaque } \\
\hline Maximum ICA plaque thickness (mm) & $3.89 \pm 1.14$ & $4.27 \pm 0.90$ & $3.61 \pm 1.22$ & 0.008 \\
\hline Total maximum ICA plaque thickness (mm) & $6.59 \pm 2.12$ & $7.28 \pm 1.84$ & $6.08 \pm 2.19$ & 0.009 \\
\hline \multicolumn{5}{|l|}{ Degree of carotid stenosis } \\
\hline Mild, n (\%) & $27(31.8 \%)$ & $11(30.6 \%)$ & $16(32.7 \%)$ & 1.000 \\
\hline Moderate, n (\%) & $14(16.5 \%)$ & $6(16.7 \%)$ & $8(16.3 \%)$ & 1.000 \\
\hline Severe, n (\%) & $28(32.9 \%)$ & $14(38.9 \%)$ & $14(28.6 \%)$ & 0.356 \\
\hline Occlusion, n (\%) & $16(18.8 \%)$ & $5(13.9 \%)$ & $11(22.4 \%)$ & 0.405 \\
\hline \multicolumn{5}{|l|}{ Reasons for referral } \\
\hline Cardiovascular ischemia-related, n (\%) & $44(51.8 \%)$ & $22(66.1 \%)$ & $22(44.9 \%)$ & 0.189 \\
\hline Cerebral ischemia-related, n (\%) & $30(35.3 \%)$ & $11(30.6 \%)$ & $19(38.8 \%)$ & 0.496 \\
\hline Asymptomatic, n (\%) & $7(8.2 \%)$ & $2(5.6 \%)$ & $5(10.2 \%)$ & 0.694 \\
\hline Other & $4(4.7 \%)$ & $1(2.8 \%)$ & $3(6.1 \%)$ & 0.634 \\
\hline
\end{tabular}

$\mathrm{LDL}-\mathrm{C}^{(\mathrm{F})}=\mathrm{TC}-\mathrm{HDL}-\mathrm{C}-\mathrm{TG} / 2.2$

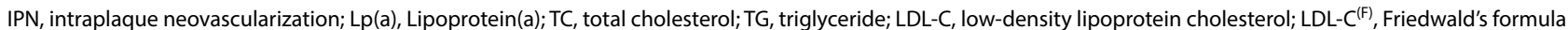
adjust low-density lipoprotein cholesterol; HDL-C, high-density lipoprotein cholesterol; Apo, apolipoprotein; ICA, Internal carotid artery

*Presented as median (interquartile range) 
Table 2 Baseline characteristics comparisons between $L p(a)<300 \mathrm{mg} / \mathrm{L}$ and $L p(a) \geq 300 \mathrm{mg} / \mathrm{L}$ of the 85 participants

\begin{tabular}{|c|c|c|c|c|}
\hline Variables & Overall $(n=85)$ & $\mathrm{Lp}(\mathrm{a})<300 \mathrm{mg} / \mathrm{L}(\mathrm{n}=62)$ & $L p(a) \geq 300 \mathrm{mg} / \mathrm{L}(\mathrm{n}=23)$ & $P$ value \\
\hline \multicolumn{5}{|l|}{ General conditions and Comorbid conditions } \\
\hline Age (year) & $68.48 \pm 8.78$ & $68.66 \pm 9.00$ & $68.00 \pm 8.35$ & 0.760 \\
\hline Male sex, n (\%) & $63(74.1 \%)$ & $45(72.6 \%)$ & $18(78.3 \%)$ & 0.782 \\
\hline Hypertension, n (\%) & $60(70.6 \%)$ & $45(72.6 \%)$ & $15(65.3 \%)$ & 0.594 \\
\hline Diabetes mellitus, n (\%) & $26(30.6 \%)$ & $21(33.9 \%)$ & $5(21.7 \%)$ & 0.427 \\
\hline Cerebral infraction, n (\%) & $21(24.7 \%)$ & $15(24.2 \%)$ & $6(26.1 \%)$ & 1.000 \\
\hline Coronary heart disease, $\mathrm{n}(\%)$ & $38(44.7 \%)$ & $24(38.7 \%)$ & $14(60.9 \%)$ & 0.087 \\
\hline Smoking history, n (\%) & $20(23.5 \%)$ & $14(22.6 \%)$ & $6(26.1 \%)$ & 0.777 \\
\hline Statin use, n (\%) & 79 (92.9\%) & $58(91.3 \%)$ & $21(91.3 \%)$ & 0.660 \\
\hline \multicolumn{5}{|l|}{ Serum lipid } \\
\hline $\operatorname{Lp}(a)(m g / L) *$ & $184(96.5-370)$ & $129(81-209.25)$ & $473(390-822)$ & $<0.0001$ \\
\hline $\mathrm{TC}(\mathrm{mmol} / \mathrm{L})$ & $4.49 \pm 1.21$ & $4.50 \pm 1.31$ & $4.48 \pm 0.90$ & 0.935 \\
\hline $\mathrm{TG}(\mathrm{mmol} / \mathrm{L}) *$ & $1.34(1.04-1.99)$ & $1.43(1.04-2.27)$ & $1.27(0.91-1.47)$ & 0.016 \\
\hline LDL-C (mmol/L) & $2.92 \pm 0.91$ & $2.93 \pm 0.98$ & $2.89 \pm 0.70$ & 0.818 \\
\hline LDL-C ${ }^{(F)}(\mathrm{mmol} / \mathrm{L})$ & $2.13 \pm 0.75$ & $2.20 \pm 0.80$ & $1.93 \pm 0.53$ & 0.088 \\
\hline $\mathrm{HDL}-\mathrm{C}(\mathrm{mmol} / \mathrm{L}) *$ & $0.99(0.87-1.16)$ & $0.94(0.82-1.09)$ & $1.11(1.01-1.32)$ & 0.005 \\
\hline Apo(a) $(\mathrm{mmol} / \mathrm{L}) *$ & $1.16(1.01-1.28)$ & $1.10(0.97-1.30)$ & $1.19(1.12-1.26)$ & 0.060 \\
\hline $\mathrm{Apo}(\mathrm{b})(\mathrm{mmol} / \mathrm{L}) *$ & $0.79(0.64-1.01)$ & $0.78(0.62-1.02)$ & $0.80(0.70-1.03)$ & 0.602 \\
\hline \multicolumn{5}{|l|}{ Carotid plaque } \\
\hline Maximum ICA plaque thickness (mm) & $3.89 \pm 1.14$ & $3.82 \pm 1.10$ & $4.03 \pm 1.27$ & 0.501 \\
\hline Total maximum ICA plaque thickness (mm) & $6.59 \pm 2.12$ & $6.49 \pm 2.14$ & $6.84 \pm 2.10$ & 0.502 \\
\hline \multicolumn{5}{|l|}{ Degree of carotid stenosis } \\
\hline Mild, n (\%) & $27(31.8 \%)$ & $21(33.9 \%)$ & $6(26.1 \%)$ & 0.604 \\
\hline Moderate, n (\%) & $14(16.5 \%)$ & $11(17.7 \%)$ & $3(13.0 \%)$ & 0.749 \\
\hline Severe, n (\%) & $28(32.9 \%)$ & $16(25.8 \%)$ & $12(52.2 \%)$ & 0.036 \\
\hline Occlusion, n (\%) & $16(18.8 \%)$ & $14(22.6 \%)$ & $2(8.7 \%)$ & 0.215 \\
\hline \multicolumn{5}{|l|}{ Reasons for referral, $n(\%)$} \\
\hline Cardiovascular ischemia-related, n (\%) & $44(51.8 \%)$ & $33(53.2 \%)$ & $11(47.8 \%)$ & 0.808 \\
\hline Cerebral ischemia-related, n (\%) & $30(35.3 \%)$ & $18(29.0 \%)$ & $12(52.2 \%)$ & 0.073 \\
\hline Asymptomatic, n (\%) & $7(8.2 \%)$ & $7(11.3 \%)$ & $0(0.0 \%)$ & 0.091 \\
\hline Other & $4(4.7 \%)$ & $4(6.5 \%)$ & $0(0.0 \%)$ & 0.296 \\
\hline
\end{tabular}

$\mathrm{LDL}-\mathrm{C}(\mathrm{F})=\mathrm{TC}-\mathrm{HDL}-\mathrm{C}-\mathrm{TG} / 2.2$

Lp(a), Lipoprotein(a); TC, cholesterol; TG, triglyceride; LDL-C, low-density lipoprotein cholesterol; LDL-C ${ }^{(F)}$, Friedwald's formula adjust low-density lipoprotein cholesterol; HDL-C, high-density lipoprotein cholesterol; Apo, apolipoprotein; ICA, Internal carotid artery

* Presented as median (interquartile range)

concentration and IPN grade (IPN group vs No IPN group), with stepwise adjustment for covariates including age, sex and comorbid conditions (model 1), total cholesterol, triglyceride, low-density lipoprotein cholesterol calculated by Friedwald's formula, high-density lipoprotein cholesterol, apolipoprotein A and apolipoprotein B (model 2), maximum ICA plaque thickness and total ICA maximum plaque thickness, degree of carotid stenosis and ICA occlusion (model 3). Meanwhile, participants were divided into two groups according to $\mathrm{Lp}(\mathrm{a})$ concentration $(\geq 300 \mathrm{mg} / \mathrm{L}$ and $<300 \mathrm{mg} / \mathrm{L}$ ). Univariate and multivariate binary logistic regression analyses were then performed to evaluate the association with IPN grade, adjusting for model 1, model 2 and model 3. All analyses were performed with SPSS version 22.0 for Windows, and a two-sided $P$ value of less than 0.05 was considered to indicate statistical significance.

\section{Results}

\section{Participant characteristics}

The characteristics of the participants are shown in Table 1 (IPN group vs No IPN group) and Table 2 (Lp $(\mathrm{a}) \geq 300 \mathrm{mg} / \mathrm{L}$ vs $<300 \mathrm{mg} / \mathrm{L}$ ). All 85 consecutive patients, that we had complete data for the binary logistic regression analysis, were seen in Guangdong General Hospital from January 2017 to January 2020. The mean 
age of the population was $68.48 \pm 8.78$ years. More than $70 \%$ of the participants were male, with $92.9 \%$ of the participants receiving statin therapy. Approximately 20\% were smokers, with a similar proportion suffering from diabetes mellitus and cerebral infarction. Slightly fewer than half of the participants had coronary heart disease, and $70 \%$ had hypertension. Half of the patients (51.8\%) admitted for cardiovascular ischemia-related reasons, including the symptom of chest pain or shortness of breath. While other $35.3 \%$ patients admitted for cerebral ischemia-related reasons including dizzy, blurred vision or unilateral limb weakness and $8.2 \%$ patients suffered from asymptomatic carotid stenosis. The IPN group tended to have greater maximum ICA plaque thickness and total maximum ICA plaque thickness compared to No IPN group, while compared to $<300 \mathrm{mg} / \mathrm{L}$ group, it was not significant in the $\mathrm{Lp}(\mathrm{a}) \geq 300 \mathrm{mg} / \mathrm{L}$ group. And $\mathrm{Lp}(\mathrm{a}) \geq 300 \mathrm{mg} / \mathrm{L}$ group have lower TG and higher HDL-C level than the $\mathrm{Lp}(\mathrm{a})<300 \mathrm{mg} / \mathrm{L}$ group.

Spearman's correlation analysis was performed to evaluate whether $L p(a)$ was associate with ICA plaque thickness or total ICA plaque thickness, degree of ICA stenosis, ICA occlusion. Neither the ICA plaque thickness (correlation coefficient $=0.205, P$ value $=0.060$ ) nor the total ICA plaque thickness (correlation coefficient $=0.158, P$ value $=0.149$ ) was correlated with plasm $\mathrm{Lp}$ (a) concentration. Likewise, both of the degree of ICA stenosis (correlation coefficient $=0.118, P$ value $=0.281$ ) and ICA occlusion (correlation coefficient $=-0.027, P$ value $=0.806$ ) were also not correlated with $L p(a)$ concentration. After being divided into two groups based on $\mathrm{Lp}(\mathrm{a})$ concentration, there were similarly not association between the ICA plaque thickness, total ICA plaque thickness, degree of ICA stenosis, ICA occlusion and whether $\mathrm{Lp}(\mathrm{a}) \geq 300 \mathrm{mg} / \mathrm{L}$ or not.(Table 3 ).

Table $4 a$ shows that $\mathrm{Lp}(\mathrm{a})$, in the univariate analysis, was a significant predictor of IPN in carotid stenosis patients, with per $100 \mathrm{mg} / \mathrm{L}$ increasing associated with 1.238 -fold higher hazard $(95 \%$ CI 1.020, 1.503, P value $=0.031)$ of total $I P N \geq 2$. After stepwise adjusting for covariates, per $100 \mathrm{mg} / \mathrm{L}$ increasing associated
Table 4 (a) Association between Lp(a) (per $100 \mathrm{mg} / \mathrm{L}$ ) and IPN group, (b) Association between Lp(a) $(\geq 300 \mathrm{mg} / \mathrm{L}$ vs $<300 \mathrm{mg} / \mathrm{L})$ and IPN group

\begin{tabular}{|c|c|c|}
\hline & OR $(95 \% \mathrm{Cl})$ & $P$ value \\
\hline \multicolumn{3}{|l|}{ (a) } \\
\hline Unadjusted & $1.238(1.020,1.503)$ & 0.031 \\
\hline Model 1 & $1.333(1.074,1.655)$ & 0.009 \\
\hline Model 2 & $1.321(1.059,1.648)$ & 0.014 \\
\hline Model 3 & $1.305(1.045,1.628)$ & 0.019 \\
\hline \multicolumn{3}{|l|}{ (b) } \\
\hline Unadjusted & $2.828(1.055,7.580)$ & 0.039 \\
\hline Model 1 & $3.260(1.174,9.058)$ & 0.023 \\
\hline Model 2 & $2.798(0.975,8.033)$ & 0.056 \\
\hline Model 3 & $2.411(0.838,6.936)$ & 0.103 \\
\hline
\end{tabular}

Lp(a), Lipoprotein(a); IPN, intraplaque neovascularization; $\mathrm{OR}$, odds ratio; $\mathrm{Cl}$, Confidence interval

Model 1: adjusted for age, sex, smoking, hypertension, diabetes mellitus, cerebral fraction, coronary heart disease and statin therapy

Model 2: adjusted for model 1 plus total cholesterol, triglyceride, low-density lipoprotein cholesterol calculated by Friedwald's formula, high-density lipoprotein cholesterol, apolipoprotein A and apolipoprotein B

Model 3: adjusted for model 1, model 2 plus maximum plaque thickness and total carotid maximum plaque thickness, degree of carotid stenosis and ICA occlusion

with 1.305-fold higher hazard (95\% CI 1.045, 1.628, $P$ value $=0.019)$ of total $I P N \geq 2$.

$\mathrm{Lp}(\mathrm{a}) \geq 300 \mathrm{mg} / \mathrm{L}$ group, in the unadjusted model, was associated with 2.828-fold higher hazard (95\% CI $1.055,7.580, P$ value $=0.039)$ of total $I P N \geq 2$ vs $\mathrm{Lp}(\mathrm{a})<300 \mathrm{mg} / \mathrm{L}$. After stepwise adjusting for other lipid parameters (Model 2) and maximum plaque thickness, total carotid maximum plaque thickness, degree of carotid stenosis, ICA occlusion (Model 3), the association did not reach statistical difference. (Table $4 \mathrm{~b}$ ).

\section{Discussion}

Our study showed an association between plasma Lp(a) concentrations and IPN of the carotid artery confirmed by CEUS in patients with carotid stenosis, independent

Table 3 Association between Lp(a) and maximum ICA plaque thickness and total ICA maximum plaque thickness

\begin{tabular}{|c|c|c|c|c|}
\hline & \multicolumn{2}{|l|}{ Lp(a) (mg/L) } & \multicolumn{2}{|c|}{$\mathrm{Lp}(\mathrm{a})(\geq 300 \mathrm{mg} / \mathrm{L}$ vs < $300 \mathrm{mg} / \mathrm{L})$} \\
\hline & Correlation coefficient & $P$ value & Correlation coefficient & $P$ value \\
\hline Maximum ICA plaque thickness (mm) & 0.205 & 0.060 & 0.118 & 0.283 \\
\hline Total ICA maximum plaque thickness (mm) & 0.158 & 0.149 & 0.097 & 0.379 \\
\hline Degree of ICA stenosis & 0.118 & 0.281 & 0.022 & 0.845 \\
\hline ICA occlusion & -0.027 & 0.806 & -0.158 & 0.149 \\
\hline
\end{tabular}

Lp(a), Lipoprotein(a); ICA, Internal carotid artery 
of other factors, such as age, sex, comorbid conditions, other lipid parameters, plaque thickness and degree of ICA stenosis. A higher plasma Lp(a) concentration was found to be significantly related to a higher risk of IPN, while both the plaque thickness and severity of ICA stenosis were not found to be related in this regard.

Plaque instability and progression are largely related to extensive IPN, which adds plaque susceptibility to rupture or haemorrhage [16]. Lp(a) has been associated with carotid stenosis and plaque stability [5]. Our study found that plasma Lp(a) was linked to IPN grade, suggesting that a higher plasma Lp(a) concentration may accelerate IPN formation and affect plaque stability, leading to cardiovascular and cerebrovascular events $[4,17,18]$.

Furthermore, Johri Amer et al. reported that in those patients with severe coronary lesions (whose coronary artery stenosis $\geq 70 \%$ ), IPN grade of the carotid artery was associated with coronary lesion degree and complexity [19]. A recent study has demonstrated that carotid plaque neovascularization could predict significant and complex coronary artery disease (CAD) and future cardiovascular events after investigating carotid IPN in 459 stable angina patients referred for coronary angiography [4]. When those results are considered alongside the findings of this study, it seems that $\mathrm{Lp}(\mathrm{a})$ accelerates not only carotid IPN formation, but also coronary artery plaque, which corresponds with previous studies showing that plaque instability frequently co-exists at multiple vascular bed [16, 20, 21]. In our study, when we classified patients into IPN groups in terms of the CEUS grade on both sides of the carotid IPN added up to $\geq 2$, we found that $83.8 \%$ of participants in the IPN group were affected on both sides, indicating that most of the patients had plaque instability at multiple sites.

Based on the high degree of homology between apo(a) and plasminogen [8], a number of researches found that some of apo(a) fragments played a role of anti-angiogenesis which was similar to the function of plasminogen $[9$, 10]. Nevertheless, the above results were from the small samples study in vitro, there is still lack of pathophysiological role of the anti-angiogenic or angiogenic activity in humans [22]. Meanwhile, the concentration of Lp(a) tested in most studies was far below the clinical risk threshold. Although Iwabayashi Masaaki and colleagues found the $\operatorname{Lp}(\mathrm{a})$ impaired the function of endothelial cells and endothelial progenitor cells from human aortic, leading to tubule formation inhibit, the concentration of $\mathrm{Lp}$ (a) treated in this experiment was only $5 \mathrm{mg} / \mathrm{dL}$ [23]. At the higher concentrations, Liu L et al. has demonstrated the effect on stimulation of migration and proliferation of human umbilical-vein endothelial cells [11]. In this recent paper, we detected IPN in carotid stenosis patients sensitively and invasively by use of CEUS and compared Lp(a) concentration between two groups, indirectly demonstrated that $\mathrm{Lp}(\mathrm{a})$ may potentially result in plaque stabilization by the mechanism of avoiding IPN formation. Also, further large randomized controlled studies are warranted to validate.

In addition, our results support that lower $\mathrm{Lp}(\mathrm{a})$ would be worthy of attention to prevent cardiovascular and cerebrovascular events, especially given that statins, the most used lipid-lowering drugs, cannot reduce $L p(a)$ levels. Proprotein convertase subtilisin/Kexin type 9 (PCSK9) inhibitors have been confirmed to lower Lp(a) and should be considered as an independent treatment after acute coronary syndrome [24, 25]. Clinical trials, however, have shown that $\mathrm{Lp}(\mathrm{a})$ levels have only been reduced by $20-30 \%$ [26-28]. Other traditional $\mathrm{Lp}(\mathrm{a})$ lowering approaches, such as the use of niacin, mipomersen, lomitapide, and so on, have been showed that the limited and non-specific effect to lower Lp(a) with intolerable side effects, invasive procedures, and high expense [29]. However, the apo(a) ASO IONIS-Apo(a)-LRX has recently been shown to significantly reduce $L p(a)$ levels in phase 2 clinical trials with good tolerance [30]. There is ongoing phase 3 RCT trial [Lp(a)HORIZON, NCT04023552] and it may become a promising drug for the management of elevated $L p(a)$ in the future. To date, large scale randomized controlled trials have yet to be conducted to determine the precise cardiovascular benefits of lowering $L p(a)$ and further research is needed.

\section{Limitations}

This study had several limitations. First, this was an observational study, with limited possibilities to draw causal inferences. Second, it was a single-centre study, consisting of only 85 patients with carotid stenosis, and all the patients were diagnosed and treated at Guangdong General Hospital. Therefore, our study findings cannot be readily generalized, and future studies with populations of different ethnicities and comprising multiple centres are recommended. Third, our study did not take genetic variants into consideration, although plasma $L p(a)$ levels are mainly determined by genetic factors while are not significantly reduced through lifestyle interventions. Therefore, further studies using genetic approaches are warranted. What's more, while more than $90 \%$ of our participations were treated by statin regimen, LDL-C levels were above recommended thresholds that would contribute to IPN in the plaque which may bias the relationship between $\mathrm{LP}(\mathrm{a})$ concentration and IPN grade. However, after adjusting other lipid parameters, the relationship between $\mathrm{Lp}(\mathrm{a})$ concentration and IPN grade still remained statistical significance. But for the small sample sizes, large cohort studies or LDL-C-matched 
cohort studies are also warranted. Another limitation is histological validation could not perform, whether the observed relationship is affected by inflammatory component of Lp(a). Sensitively determining IPN by CEUS, however, has been widely accepted [3, 4]. So, there is reason to believe the association observed in this study was mainly due to the effect on angiogenesis. Finally, follow-up data were not collected for cardiovascular and cerebrovascular disease events. However, the relationship between $\mathrm{Lp}(\mathrm{a})$ levels and prognosis with carotid stenosis deserves further study.

\section{Conclusions}

Plasma Lp(a) concentrations were found to be independently associated with IPN in patients with carotid stenosis. As the concentration of $\mathrm{Lp}(\mathrm{a})$ increases, the risk of IPN increases. Lowering plasma Lp(a) levels may help to maintain plaque stability through slowing down IPN formation, as assessed using CEUS. Large prospective studies assessing the utility of $L p(a)$ to predict IPN in the clinical setting are required. Randomised clinical trials are needed to test whether substantial reductions in $\mathrm{Lp}$ (a) concentrations using the various treatments identified, most notably, the apo(a) ASO IONIS-Apo(a)-LRX, may facilitate improved management of individuals with high Lp(a) levels.

\begin{abstract}
Abbreviations
Lp(a): Lipoprotein(a); ASCVD: Arteriosclerotic cardiovascular disease; IPN: Intraplaque neovascularization; CEUS: Contrast-enhanced ultrasound; TC: Cholesterol; TG: Triglyceride; LDL-C: Low-density lipoprotein cholesterol; LDL: Low-density lipoprotein; apo: Apolipoprotein; OR: Odds ratios; CAD: Coronary artery disease; ICA: Internal carotid artery.
\end{abstract}

\section{Acknowledgments}

Not applicable.

\section{Authors' contributions}

Dr. Shuang Xia contributed to the conception of the study. Dr. Weida Qiu performed the data analyses and wrote the manuscript. Dr. Anping Cai revised the paper. Professor Liwen Li provided valuable guidance at every stage in the writing of this thesis. Dr. Bo Kong performed the measurements on contrastenhanced ultrasound. Dr. Lan Xu and Dr. Zejia Wu entered and edited much of the data used in these analyses. All authors read and approved the final manuscript.

\section{Funding}

This work was supported by the Guangdong Medical Science and Technology Research Fund Project [Grant Number A2017293] and the Natural Science Foundation of Guangdong Province [Grant Number 2018A030310016].

\section{Availability of data and materials}

The datasets generated and analysed during the current study are not publicly available due to the privacy protection and a number of researches on $L p(a)$ may be continued, but are available from the corresponding author (e-mail:gdghllw@163.com) on reasonable request. The processed data required to reproduce these findings cannot be shared at this time as the data also form part of an ongoing study.

\section{Declarations}

\section{Ethics approval and consent to participate}

This retrospective investigation was approved by the Research Ethics Committee of Guangdong General Hospital, Guangdong Academy of Medical Sciences. [No. GDREC2017172h]. Each participant provides written informed consent to collect all data before the study and was anonymized before analyses.

\section{Consent for publication}

Not applicable.

\section{Competing interests}

The authors declare that they have no competing interests.

\section{Author details}

${ }^{1}$ The Second School of Clinical Medicine, Southern Medical University, Guangzhou 510515, China. ${ }^{2}$ Department of Cardiology, Guangdong Cardiovascular Institute, Guangdong Provincial People's Hospital, Guangdong Academy of Medical Sciences, 106 of Zhongshan 2nd Road, Guangzhou 510100, Guangdong, China.

Received: 28 January 2021 Accepted: 22 April 2021

Published online: 09 June 2021

\section{References}

1. Saba L, Yuan C, Hatsukami TS, Balu N, Qiao Y, DeMarco JK, et al. Carotid artery wall imaging: perspective and guidelines from the ASNR Vessel Wall Imaging Study Group and Expert Consensus Recommendations of the American Society of Neuroradiology. AJNR Am J Neuroradiol. 2018;39(2):E9-31.

2. Giannarelli C, Ibanez B, Cimmino G, Garcia Ruiz JM, Faita F, Bianchini E, et al. Contrast-enhanced ultrasound imaging detects intraplaque neovascularization in an experimental model of atherosclerosis. JACC Cardiovasc Imaging. 2010;3:1256-64.

3. Zamani M, Skagen K, Scott H, Lindberg B, Russell D, Skjelland M. Carotid plaque neovascularization detected with superb microvascular imaging ultrasound without using contrast media. Stroke. 2019;50(11):3121-7.

4. Mantella LE, Colledanchise KN, Hétu MF, Feinstein SB, Abunassar J, Johri AM. Carotid intraplaque neovascularization predicts coronary artery disease and cardiovascular events. Eur Heart J Cardiovasc Imaging. 2019;20(11):1239-47.

5. Ooi EM, Ellis KL, Barrett PHR, Watts GF, Hung J, Beilby JP, et al. Lipoprotein(a) and apolipoprotein(a) isoform size: associations with angiographic extent and severity of coronary artery disease, and carotid artery plaque. Atherosclerosis. 2018;275:232-8.

6. Klein JH, Hegele RA, Hackam DG, Koschinsky ML, Huff MW, Spence JD. Lipoprotein(a) is associated differentially with carotid stenosis, occlusion, and total plaque area. Arterioscler Thromb Vasc Biol. 2008;28:1851-6.

7. Hippe DS, Phan BAP, Sun J, Isquith DA, O'Brien KD, Crouse JR, Anderson T, Huston J, Marcovina SM, Hatsukami TS, Yuan C, Zhao X-Q. Lp(a) (Lipoprotein(a)) levels predict progression of carotid atherosclerosis in subjects with atherosclerotic cardiovascular disease on intensive lipid therapy: an analysis of the AIM-HIGH (Atherothrombosis intervention in metabolic syndrome with low HDL/high triglycerides: impact on Global Health Outcomes) carotid magnetic resonance imaging substudy-brief report. Arterioscler Thromb Vasc Biol. 2018;38:673-8.

8. Cai A, Li L, Zhang Y, Mo Y, Mai W, Zhou Y. Lipoprotein(a): a promising marker for residual cardiovascular risk assessment. Dis Markers. 2013;35:551-9.

9. Schulter V, Koolwijk P, Peters E, Frank S, Hrzenjak A, Graier WF, van Hinsbergh VW, Kostner GM. Impact of apolipoprotein(a) on in vitro angiogenesis. Arterioscler Thromb Vasc Biol. 2001;21:433-8.

10. Liu L, Boffa MB, Koschinsky ML. Apolipoprotein(a) inhibits in vitro tube formation in endothelial cells: identification of roles for Kringle $V$ and the plasminogen activation system. PLoS ONE. 2013;8:e52287.

11. Liu L, Craig AW, Meldrum HD, Marcovina SM, Elliott BE, Koschinsky ML. Apolipoprotein(a) stimulates vascular endothelial cell growth 
and migration and signals through integrin alphaVbeta3. Biochem J. 2009;418:325-36.

12. Lou XJ, Kwan HH, Prionas SD, Yang ZJ, Lawn RM, Fajardo LF. Despite its homology to angiostatin apolipoprotein(a) does not affect angio-genesis. Exp Mol Pathol. 1998;65:53-63.

13. Touboul P-J, Hennerici MG, Meairs S, Adams H, Amarenco P, Bornstein N, Csiba L, Desvarieux M, Ebrahim S, Hernandez Hernandez R, Jaff M, Kownator S, Naqvi T, Prati P, Rundek T, Sitzer M, Schminke U, Tardif J-C, Taylor A, Vicaut E, Woo KS. Mannheim carotid intima-media thickness and plaque consensus (2004-2006-2011). An update on behalf of the advisory board of the 3rd, 4th and 5th watching the risk symposia, at the 13th, 15th and 20th European Stroke Conferences, Mannheim, Germany, 2004, Brussels, Belgium, 2006, and Hamburg, Germany, 2011. Cerebrovasc Dis. 2012;34:290-6.

14. Brott TG, Halperin JL, Abbara S, Bacharach JM, Barr JD, Bush RL, Cates CU, Creager MA, Fowler SB, Friday G, Hertzberg VS, Mclff EB, Moore WS, Panagos PD, Riles TS, Rosenwasser RH, Taylor AJ. 2011ASA/ACCF/AHA/AANN/ AANS/ACR/ASNR/CNS/SAIP/SCAI/SIR/SNIS/SVM/SVS guideline on the management of patients with extracranial carotid and vertebral artery disease: executive summary: a report of the American College of Cardiology Foundation/American Heart Association Task Force on Practice Guidelines, and the American Stroke Association, American Association of Neuroscience Nurses, American Association of Neurological Surgeons, American College of Radiology, American Society of Neuroradiology, Congress of Neurological Surgeons, Society of Atherosclerosis Imaging and Prevention, Society for Cardiovascular Angiography and Interventions, Society of Interventional Radiology, Society of Neurolnterventional Surgery, Society for Vascular Medicine, and Society for Vascular Surgery. J Am Coll Cardiol. 2011;57:1002-44.

15. Zhang Q, Li C, Han H, Dai W, Shi J, Wang Y, et al. Spatio-temporal quantification of carotid plaque neovascularization on contrast enhanced ultrasound: correlation with visual grading and histopathology. Eur J Vasc Endovasc Surg. 2015;50(3):289-96.

16. Shah BN, Gujral DM, Chahal NS, Harrington KJ, Nutting CM, Senior R. Plaque neovascularization is increased in human carotid atherosclerosis related to prior neck radiotherapy: a contrast-enhanced ultrasound study. JACC Cardiovasc Imaging. 2016;9(6):668-75.

17. Kan Y, He W, Ning B, Li HX, Wei SJ, Yu TF. The correlation between calcification in carotid plaque and stroke: calcification may be a risk factor for stroke. Int J Clin Exp Pathol. 2019;12(3):750-8.

18. Grönberg C, Bengtsson E, Fredrikson GN, Nitulescu M, Asciutto G, Persson A, et al. Human carotid plaques With high levels of interleukin-16 are associated With reduced risk for cardiovascular events. Stroke. 2015:46(10):2748-54.

19. Johri AM, Behl P, Hétu MF, Haqqi M, Ewart P, Day AG, et al. Carotid ultrasound maximum plaque height-A sensitive imaging biomarker for the assessment of significant coronary artery disease. Echocardiography. 2016;33(2):281-9.
20. Rothwell PM, Villagra R, Gibson R, Donders RC, Warlow CP. Evidence of a chronic systemic cause of instability of atherosclerotic plaques. Lancet. 2000;355(9197):19-24.

21. Boden-Albala B, Kargman DE, Lin IF, Paik MC, Sacco RL, Berglund L. Increased stroke risk and lipoprotein(a) in a multiethnic community: The Northern Manhattan Stroke Study. Cerebrovasc Dis. 2010;30(3):237-43.

22. Kalaivani V, Jaleel A. Apolipoprotein(a), an enigmatic anti-angiogenic glycoprotein in human plasma: a curse or cure? Pharmacol Res. 2020:158:104858.

23. Iwabayashi M, Taniyama Y, Sanada F, Azuma J, lekushi K, Okayama K, Chatterjee A, Rakugi H, Morishita R. Inhibition of Lp(a)-induced functional impairment of endothelial cells and endothelial progenitor cells by hepatocyte growth factor. Biochem Biophys Res Commun. 2012;423:79-84.

24. Greco MF, Sirtori CR, Corsini A, Ezhov M, Sampietro T, Ruscica M. Lipoprotein(a) lowering-from lipoprotein apheresis to antisense oligonucleotide approach. J Clin Med. 2020;9(7):2103.

25. Bittner VA, Szarek M, Aylward PE, et al. Effect of alirocumab on lipoprotein(a) and cardiovascular risk after acute coronary syndrome. J Am Coll Cardiol. 2020;75:133-44.

26. Gaudet D, Kereiakes DJ, McKenney JM, Roth EM, Hanotin C, Gipe D, et al. Effect of alirocumab, a monoclonal proprotein convertase subtilisin/ kexin 9 antibody, on lipoprotein(a) concentrations (a pooled analysis of $150 \mathrm{mg}$ every two weeks dosing from phase 2 trials). Am J Cardiol. 2014;114(5):711-5.

27. Shapiro MD, Minnier J, Tavori H, Kassahun H, Flower A, Somaratne R, et al. Relationship Between low-density lipoprotein cholesterol and lipoprotein(a) lowering in response to PCSK9 inhibition With evolocumab. J Am Heart Assoc. 2019:8(4):e010932.

28. Gaudet D, Watts GF, Robinson JG, Minini P, Sasiela WJ, Edelberg J, et al. Effect of alirocumab on lipoprotein(a) over $\geq 1.5$ years (from the Phase 3 ODYSSEY Program). Am J Cardiol. 2017;119(1):40-6.

29. Wu MF, Xu KZ, Guo YG, Yu J, Wu Y, Lin LM. Lipoprotein(a) and atherosclerotic cardiovascular disease: current understanding and future perspectives. Cardiovasc Drugs Ther. 2019;33(6):739-48.

30. Tsimikas S, Karwatowska-Prokopczuk E, Gouni-Berthold I, Tardif J-C, Baum SJ, Steinhagen-Thiessen E, Shapiro MD, Stroes ES, Moriarty PM, Nordestgaard BG, Xia S, Guerriero J, Viney NJ, Dea L, Witztum JL. AKCEAAPO(a)-LRx Study Investigators. Lipoprotein(a) reduction in persons with cardiovascular disease. N Engl J Med. 2020;382(3):244-55.

\section{Publisher's Note}

Springer Nature remains neutral with regard to jurisdictional claims in published maps and institutional affiliations.

Ready to submit your research? Choose BMC and benefit from:

- fast, convenient online submission

- thorough peer review by experienced researchers in your field

- rapid publication on acceptance

- support for research data, including large and complex data types

- gold Open Access which fosters wider collaboration and increased citations

- maximum visibility for your research: over $100 \mathrm{M}$ website views per year

At BMC, research is always in progress.

Learn more biomedcentral.com/submissions 